\title{
BLENDS OF POLY(VINYL PYRIDINE)S AND TWO DIHYDRIC PHENOLS: THERMAL AND INFRARED SPECTROSCOPIC STUDIES. PART II.
}

\author{
NICOLÁS GATICA* AND NANCY ALVARADO \\ Departamento de Polímeros, Facultad de Ciencias Químicas, Universidad de Concepción, Casilla 160-C, Concepción, Chile.
}

(Received: September 15, 2008 - Accepted: April 28,2009)

\begin{abstract}
The miscibility behavior in blends containing poly(4-vinyl pyridine) (P4VPy) and poly(2-vinyl pyridine) (P2VPy) as polymer components and the dihydric phenols 4,4'-thiodiphenol (TDP) and 4,4'-methylendiphenol (MDP) as low molecular weight compounds (LMWC), was studied by Differential Scanning Calorimetry (DSC) and Fourier Transform Infrared Spectrophotometry (FTIR) as main analytical techniques. The glass transition of P4VPy and the melting of TDP and MDP, were found to be significantly affected when the compounds were blended. This result was attributed to the miscibility between them, as a direct consequence of the specific interactions between the blend components. FTIR was used to investigate these interactions. The formation of intermolecular hydrogen bonds between the pyridine nitrogen atoms and the hydroxyl groups of TDP and MDP were discovered. When P2VPy was the macromolecular component, a difference was observed in the DSC behavior, which was attributed to a steric hindrance effect. Thermogravimetric and viscometry analysis were also used as additional techniques to complement the FTIR and DSC measurements performed.
\end{abstract}

Keywords: blends, poly(4-vinyl pyridine), poly(2-vinyl pyridine), 4,4'-thiodiphenol, 4,4'-methylendiphenol, hydrogen bond, low molecular weight compounds.

\section{INTRODUCTION}

There has been considerable interest in the study of binary blends containing polymeric and non-polymeric compounds. When two (or more) polymers are blended to obtain miscible blends with better properties, the blending Gibbs free energy $\left(\Delta \mathrm{G}^{\mathrm{M}}\right)$ is controlled by its enthalpic contribution $\left(\Delta \mathrm{H}^{\mathrm{M}}\right)$ because the entropic factor $\left(\Delta \mathrm{S}^{\mathrm{M}}\right)$ is normally unfavorable due to the blend components' high molecular weight. As a result, miscible polymer-polymer blends are obtained when the polymers contain complementary chemical functions ${ }^{1-10}$, resulting in a favorable blending enthalpy $\left(\Delta \mathrm{H}^{\mathrm{M}}<0\right)$. When one of the blend components is a non-polymeric compound, i. e., a low molecular weight compound (LMWC), the unfavorable entropic factor is negligible. Thus, it is generally possible to obtain miscible polymer-LMWC blends, in which the properties of the macromolecular component are modified $d^{11-13}$.

At present, LMWCs are included as additives in polymeric materials in industrial processes to modify their properties and increase the applications in this field. Antioxidants, stabilizers, plasticizers, lubricants, flame retardants and curatives, among other compounds, are the most used ones. For instance, dialkyl phtalates are incorporated as plasticizers for poly(vinyl chloride), improving its processability and flexibility ${ }^{14}$. Poly-unsaturated elastomers are oxidation-sensitive materials and thus antioxidants are often added after vulcanization processes to protect the polymeric material during drying and storing. Two examples of LMWCs used for these purposes are butylated hydroxytoluene and 2,4-bis(octyltiomethyl)-6-methyl pheno ${ }^{15}$. Triethanol amines and triisopropanol amines are cited in the literature as crosslinking and curing agents in injection molding formulations for poly(urethanes) ${ }^{16}$, improving, in this case, properties such as impact and heat resistance. Alcanol amines are also used to increase the thermal stability of polystyrene and vinyl chloride copolymers ${ }^{16}$. However, in most cases, polymeric materials with good properties are obtained as the result of empirical or semi-empirical assays, which allow a controlled modification of the final properties. However, there are few systematic studies on the thermodynamic characterization of polymerLMWC blends.

The presence of potentially interacting chemical functions is a common characteristic of polymer-polymer and polymer-LMWC blends, with which the blended systems can be characterized. Thus, some functionalized LMWCs have been used to obtain this kind of blends ${ }^{17-23}$. For example, 4,4'-thiodiphenol (TDP) and 4,4'-methylendiphenol (MDP) can be used to obtain miscible blends because of their particular chemical structure, which promotes miscibility with several polymer pairs ${ }^{20-23}$. TDP and MDP are efficient proton-donor LMWCs that easily generate hydrogen bonding because of the good spatial disposition of the hydroxyl group in the para position of the aromatic ring with relation to the adjoining ring. This characteristic suggests that TDP and MDP can be considered as potentially interacting LMWCs. Their structural formulae are presented in Figure 1. On the other hand, poly(vinylpyridines), such as P4VPy and P2VPy (Figure 1) are well-known functionalized vinyl polymers previously used in polymer blends. They present interesting structural properties as the presence of pyridine nitrogen atoms with basic character, which can interact with other blend components by means of different kinds of specific interactions, such as hydrogen bonding or dipolar interactions, to form miscible polymer blends ${ }^{1,24-30}$.

The aim of this work is to study the compatibility of polymer-LMWC blends to identify the effect of specific interactions on the miscibility behavior. For that, blends of P4VPy with TDP (blend C) and MDP (blend D) and blends of P2VPy with TDP (blend G) and MDP (blend H) were studied by Differential Scanning Calorimetry (DSC), Fourier Transform Infrared Spectroscopy (FTIR), Thermogravimetric Analysis (TGA) and Viscometry.

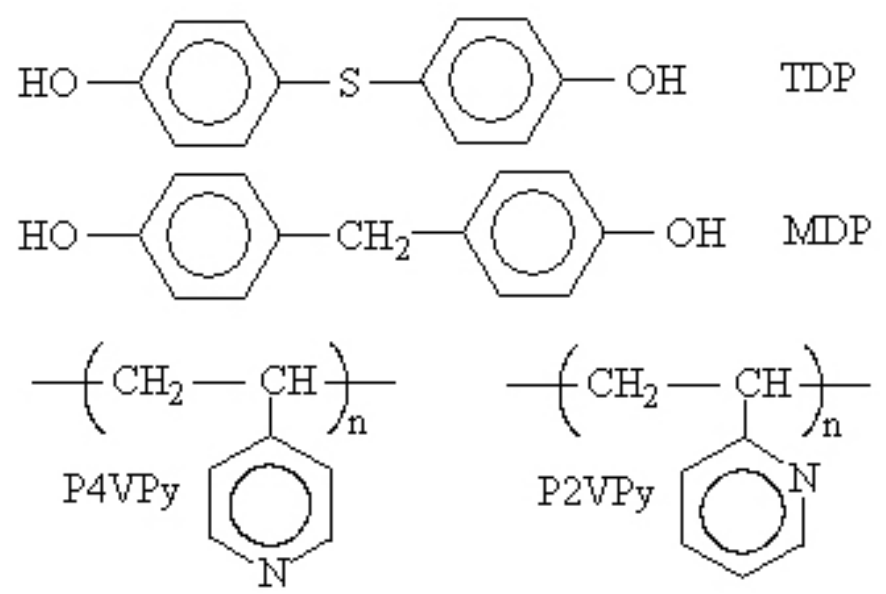

Figure 1. Structural formulae of 4,4'-thiodiphenol (TDP), 4,4'methylenediphenol (MDP), poly(4-vinyl pyridine) (P4VPy) and poly(2vinylpyridine) (P2VPy).

\section{EXPERIMENTAL}

\section{Blend components}

Aldrich's P4VPy, P2VPy, TDP and MDP were used. The weight-average molecular weight $\left(\mathrm{M}_{\mathrm{w}}\right)$ of P4VPy and P2VPy are 60,000 and ca. 40,000 g/mol respectively. The glass transition temperatures $(\mathrm{Tg})$ are $142.0{ }^{\circ} \mathrm{C}$ for P4VPy and $64.9^{\circ} \mathrm{C}$ for P2VPy. Melting points of TDP and MDP are $153.5^{\circ} \mathrm{C}$ and 163.4 respectively. 


\section{Preparation of blends}

Blends of different compositions were prepared by solution casting using methanol as solvent. Then, they were evaporated at room temperature and vacuum dried at $35{ }^{\circ} \mathrm{C}$ for $1-2$ weeks until constant weight. The blend concentration was about 2 weight $\%$.

Table 1 shows the composition and the denomination of the blends included in this work.

\section{DSC measurements}

The glass transition temperature (Tg) of P4VPy, P2VPy and blends and the melting temperatures (Tm) of TDP, MDP and blends were measured by Differential Scanning Calorimetry (DSC) from the thermograms obtained with a Differential Scanning Calorimeter Rheometric Scientific DSC Plus, with the Orchestrator program as graphical software. Samples (3-4 mg) were placed inside aluminum pans and heated under flowing nitrogen $(25 \mathrm{~mL} / \mathrm{min})$, ranging from 25 to $200{ }^{\circ} \mathrm{C}$, at $10\left({ }^{\circ} \mathrm{C} / \mathrm{min}\right)$

To minimize differences in the thermal history of the samples, the $\mathrm{Tg}$ and Tm determination was performed as follows: heating until the final temperature (dynamic stage), isothermal stage at the final temperature (static), cooling until the initial temperature (dynamic, quenching step), isothermal step at the initial temperature (static) and heating until the final temperature (dynamic). In all cases, the Tg was evaluated from the last stage.

Samples were dried under reduced pressure in a vacuum oven prior to measurements.

\section{FTIR spectra}

Infrared spectra of P4VPy, P2VPy, LMWC and their blends were recorded on a Nicolet Magna IR 550 Fourier transform infrared spectrophotometer. Spectra were recorded with a resolution of $1 \mathrm{~cm}^{-1}$. Samples were prepared directly in $\mathrm{KBr}$ pellets.

\section{TGA measurements}

Thermogravimetric measurements were performed using a thermal analyzer TGA Polymer Laboratories STA 625. Samples $(2-3 \mathrm{mg})$ were placed inside aluminum pans and heated under flowing nitrogen $(41 \mathrm{~mL} / \mathrm{min})$ ranging from 25 to $550{ }^{\circ} \mathrm{C}$ at $10{ }^{\circ} \mathrm{C} / \mathrm{min}$, obtaining the corresponding thermal decomposition profiles.

Samples were dried under reduced pressure in a vacuum oven prior to measurements.

\section{Viscometry measurements}

Intrinsic viscosity ([n]) of P4VPy, P2VPy and the different blends was determined using an Ostwald type capillary dilution viscometer in methanol at $25{ }^{\circ} \mathrm{C}$ without kinetic energy corrections. Intrinsic viscosities were obtained using the Solomon Gotessman equation ${ }^{31}$.

Table 1. Composition and denomination of the studied blends.

\begin{tabular}{|c|c|c|}
\hline Blend & $\begin{array}{c}\text { Composition } \\
\text { (weight \% in polymer) }\end{array}$ & Correlative denomination \\
\hline P4VPy + TDP (C) & $100,80,60,50,40,20,0$ & C1, C2, C3, C4, C5, C6, C7 \\
\hline P4VPy + MDP (D) & $100,80,60,50,40,20,0$ & D1, D2, D3, D4, D5, D6, D7 \\
\hline P2VPy + TDP (G) & $100,80,60,50,40,20,0$ & G1, G2, G3, G4, G5, G6, G7 \\
\hline P2VPy + MDP (H) & $100,80,60,50,40,20,0$ & H1, H2, H3, H4, H5, H6, H7 \\
\hline
\end{tabular}

\section{RESULTS AND DISCUSSION}

The individual thermograms of the $\mathrm{C}$ and $\mathrm{D}$ blends, collected in Figure 2, show a significant displacement of P4VPy's Tg toward lower values as the blend is richer in TDP or MDP. However, due to the size of the melting peaks (shown in the same Figure), it is not possible to observe the corresponding $\mathrm{Tg}$ signs. Figure 3-a shows the thermogram for the $\mathrm{C} 4$ sample (with reduced heat flow scale) as a representative example. At $\mathrm{Tg}$, the heat capacity of the sample increases, requiring more energy to keep the sample temperature equal to the reference temperature, characteristic condition of DSC. This heat flow to the sample originates a drop in the DSC curve, as can be observed in Figure 3-a. From this kind of plots, the Tg values were obtained. Figure 3-b shows the P4VPy's Tg decreasing with the LMWC content increasing, behavior known as plasticizing effect, which has been described for many blends with commercial $\mathrm{use}^{32}$. In them, the plasticizers are LMWCs that reduce the Tg of the polymer component forming the blend. They are substances that produce soft and homogeneous materials. The products obtained in such a way, are more flexible and easier to process than the pure polymer. Their principal form of acting seems to be as spacer at the molecular level. Thus, a lower energy amount is required to release the macromolecules, allowing the free rotation around the carbon-carbon bonds. Then, a decrease in the Tg values is obtained.
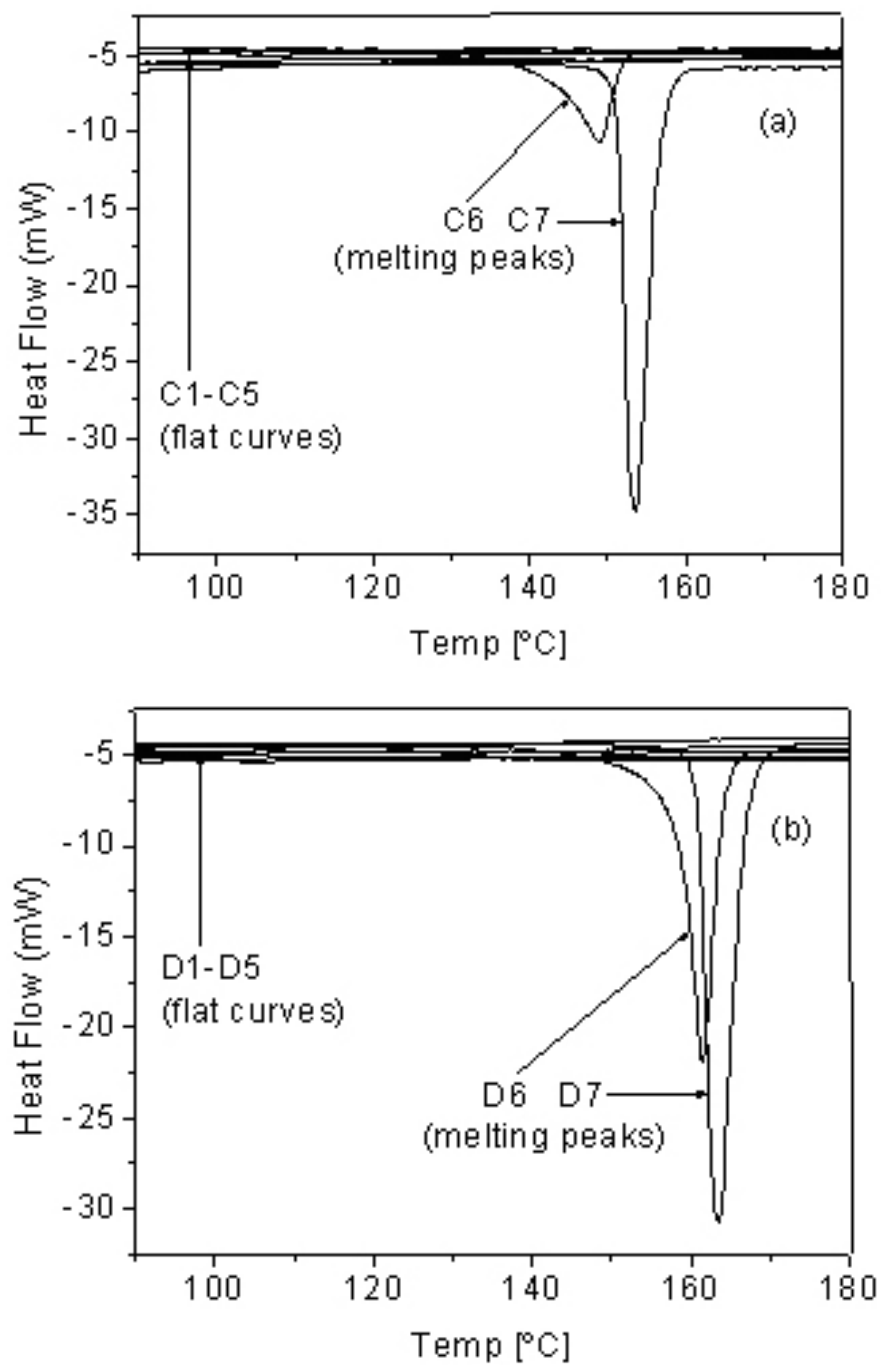

Figure 2. Thermograms of the blends a) P4VPy/TDP (C) and b) P4VPy/ MDP (D). 

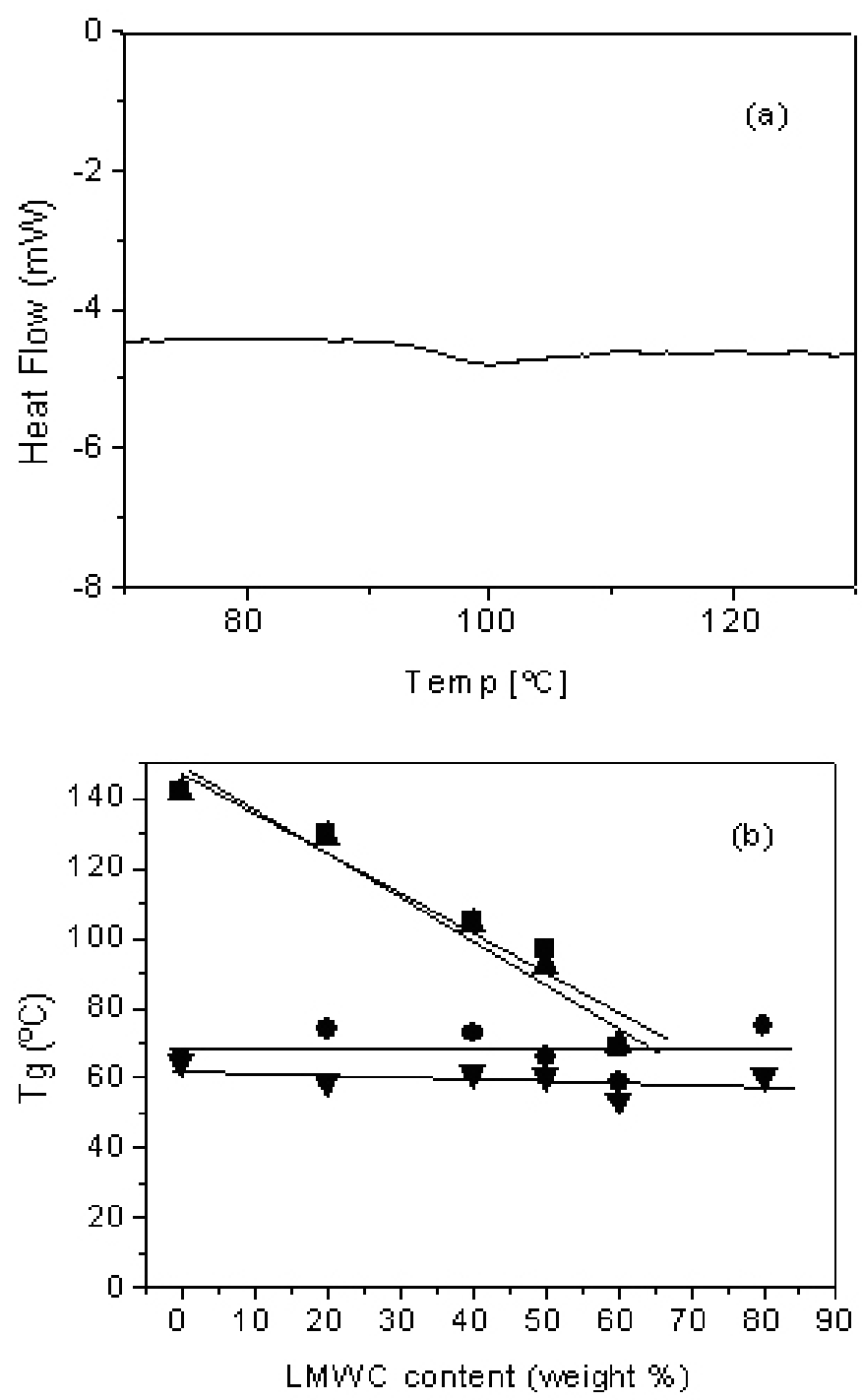

Figure 3. a) Thermogram for the $\mathrm{C} 4$ sample (50 weight \% $\mathrm{P} 4 \mathrm{VPy} /$ 50 weight $\% \mathrm{TDP})$. b) Glass transition temperature $(\mathrm{Tg})$ variation with the composition, for the blends $\mathrm{C}(\boldsymbol{\bullet}), \mathrm{D}(\boldsymbol{\Delta}), \mathrm{G}(\bullet)$ and $\mathrm{H}(\boldsymbol{\nabla})$.

When the macromolecular component is P2VPy, a clearly different behavior is observed (Figure 3-b). In both blends, the Tg does not suffer significant changes with the composition, which would reflect a lower degree of interaction between the components of the $\mathrm{G}$ and $\mathrm{H}$ blends. The presence of the P2VPy monomer unit (2-vinylpyridine, 2VPy) can give rise to this decrease in affinity between the components. 2VPy and 4-vinylpyridine (4VPy, the monomer unit of P4VPy) are isomeric structures with similar features, such as size and electron density distribution. However, they present a considerable difference in the position of the hydrogen acceptor atom. In general, the interacting functional group should be spatially accessible to favor the miscibility. If the functional group is screened, sterically hindered or self-associated, the miscibility will be affected. In the case of the 2VPy unit in a macromolecular chain, the pyridinic nitrogen atom is less accessible for a determined interaction because of it is closer to the main chain than the nitrogen atom of the 4VPy monomer unit. In the last one, the carbon chain is in para- position with respect to the heteroatom.

The thermograms of the blend $\mathrm{C}$ presented in Figure 2-a also show that TDP (C7 sample) has a melting temperature $(\mathrm{Tm})$ of $153.5{ }^{\circ} \mathrm{C}$, which decreases to $149.1{ }^{\circ} \mathrm{C}$ when the content of P4VPy is 20 weight $\%$ (C6 sample). Additionally, the fusion molar enthalpies $\left(\Delta \mathrm{H}_{\text {fus }}\right)$ were calculated from the peaks corresponding to the $\mathrm{C} 7$ and $\mathrm{C} 6$ samples. The obtained values were 36.0 and $19.2 \mathrm{~kJ} / \mathrm{mol}$ respectively. Tm and $\Delta \mathrm{H}_{\text {fus }}$ values obtained for $\mathrm{C} 7$ and $\mathrm{C} 6$ (included in Table 2) suggest that when the low molecular weight component,
TDP, is blended with the macromolecular component, P4VPy, the crystallinity of the former decreases and a lower energy amount is required to mrlt TDP in the blended state. Moreover, as can be observed in Figure 2-a, there are no fusion peaks from the $\mathrm{C} 5$ sample, i. e., 40 weight $\%$ in P4VPy, which represents the obtainment of an amorphous phase from this content of P4VPy in the blend. When the LMWC molecules are distributed between the macromolecular chains of P4VPy, a decreasing molecular order of TDP occurs, i. e., the cristallinity diminishes. This behavior suggests that some kind of intermolecular interaction must exist between TDP and P4VPy. We have described a similar behavior for the blends of poly(methyl methacrylate-co-methacrylic acid) [P(MMA-coMA)] with TDP and MDP in a previously reported work ${ }^{23}$. Moreover, Inoue et al. have reported the same behavior for blends between TDP and poly( $\varepsilon$ caprolactone) $)^{22}$.

Table 2. Melting temperatures (Tm) and fusion molar enthalpies $\left(\Delta \mathrm{H}_{\mathrm{fus}}\right)$ for specified compositions of blends $\mathrm{C}, \mathrm{D}, \mathrm{G}$ and $\mathrm{H}$.

\begin{tabular}{|c|c|c|c|}
\hline Blend & Composition & $\operatorname{Tm}\left({ }^{\circ} \mathrm{C}\right)$ & $\Delta \mathrm{H}_{\text {fus }}(\mathrm{kJ} / \mathrm{mol})$ \\
\hline $\mathrm{C}$ & $\mathrm{C} 7$ & 153.5 & 36.0 \\
\hline & $\mathrm{C} 6$ & 149.1 & 19.2 \\
\hline $\mathrm{D}$ & $\mathrm{D} 7$ & 163.4 & 34.8 \\
\hline & $\mathrm{D} 6$ & 161.4 & 31.2 \\
\hline $\mathrm{G}$ & $\mathrm{G} 7$ & 153.5 & 36.0 \\
\hline & $\mathrm{G} 6$ & 131.2 & 10.7 \\
\hline $\mathrm{H}$ & $\mathrm{H} 7$ & 163.4 & 34.8 \\
\hline & $\mathrm{H} 6$ & 158.2 & 16.9 \\
\hline
\end{tabular}

When the low molecular weight compound was MDP (with P4VPy) similar results are obtained. The values of Tm and $\Delta \mathrm{H}_{\text {fus }}$ for D7 (MDP) and D6 (MDP 80 weight \%, P4VPy 20 weight \%) obtained from Figure 2-b, are 163.4 and $161.4{ }^{\circ} \mathrm{C}$ and 34.8 and $31.2 \mathrm{~kJ} / \mathrm{mol}$ respectively (Table 2).

In both $\mathrm{C}$ and $\mathrm{D}$ blends, the content of the macromolecular component from which no melting peaks are observed, is 40 weight $\%$ (samples C5 and D5). From this composition, TDP and MDP crystallization is completely suppressed (from C5 to C2 and from D5 to D2). This polymer content is lower than observed in the previously studied systems ${ }^{23}$ [50 and 60 weight $\%$ of P(MMA-co-MA) for the blends with TDP and MDP respectively], which could be indicative of a higher interaction degree of TDP and MDP with P4VPy.

A similar behavior is obtained for blends $\mathrm{G}$ and $\mathrm{H}$. The corresponding $\mathrm{Tm}$ and $\Delta \mathrm{H}_{\text {fus }}$ values are also collected in Table 2 .

Besides the differential scanning calorimetry, Fourier transform infrared spectroscopy (FTIR) is one of the most used analytical techniques to set up compatibility between polymers ${ }^{1,2,10,33-36}$. The shifting of the band corresponding to a determined functional group is interpreted as a direct consequence of specific intermolecular interactions due to the changes in the electronic density of the chemical bonds involved in the interaction.

Figure 4 shows the FTIR spectra for the blend D as representative examples. The monomer units of P4VPy have pyridine groups whose absorption bands, corresponding to the ring deformation, appear around $993-994 \mathrm{~cm}^{-1}$. TDP and MDP have no pyridinic rings that can produce this characteristic band. Thus, any variation in this spectral zone can be directly related with a change in the pyridine group's chemical environment. If this group's basic character is considered in addition to the presence of hydrogen atoms bonded to electronegative oxygen atoms in TDP and MDP, such a change must correspond to interactions like hydrogen bonding. From the spectra shown in Figure 4, the position of the band corresponding to the deformation vibration of the pyridine groups of P4VPy was studied in the blends with TDP and MDP (Figure 5). In both cases, a shift toward higher wave number values is observed as the blend is richer in the LMWC. These results reveal the formation of hydrogen bonding between the components. This behavior has been previously described for polymerpolymer blends containing poly(vinylpyridine) $\mathrm{s}^{37}$, in which the spectral mode for the ring centered at $993 \mathrm{~cm}^{-1}$ for the non-bonding groups suffers a shift toward higher wave numbers when it forms a part of a hydrogen bond. This behavior is attributed to a stiffness increase of the associated ring. When the pyridinic group is hydrogen bonded, and consequently more rigid, a larger energy amount is required to deform the aromatic cycle, which is reflected in a higher wave number value. As can be observed in Figure 5, this shift is larger as the content of TDP and MDP increases, which is in accordance with a larger content of hydroxyl groups available for the hydrogen bond formation. 


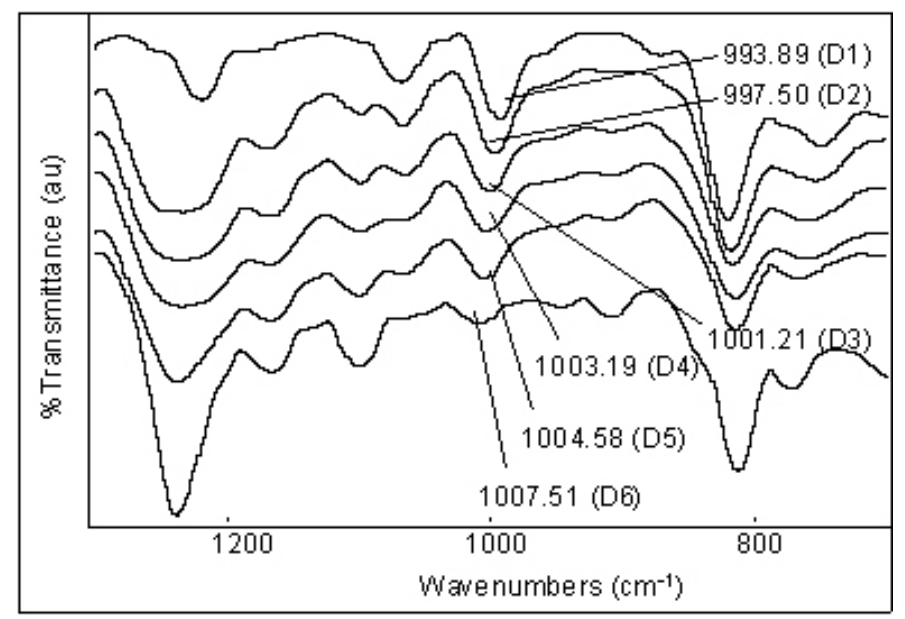

Figure 4. FTIR spectra for blend D at the $700-1300 \mathrm{~cm}^{-1}$ zone.

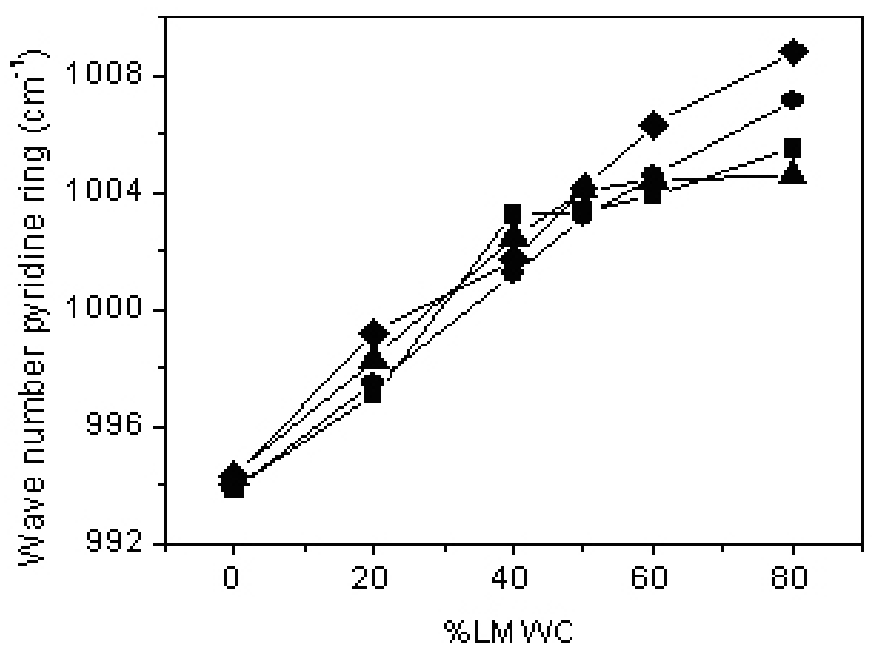

Figure 5. Wave number corresponding to the deformation absorption of the pyridine groups in the blends $\mathrm{C}(\boldsymbol{\bullet}), \mathrm{D}(\bullet), \mathrm{G}(\boldsymbol{\Delta})$ and $\mathrm{H}(\bullet)$.

When the polymer component is P2VPy (blends $\mathrm{G}$ and $\mathrm{H}$ ), the same behavior is obtained, which can be also observed in Figure 5.

It's well known that poly(4-vinylphenol) ( $\mathrm{P} 4 \mathrm{VPh})$ and copolymers bearing the 4-vinyl phenol (4VPh) unit are a part of many miscible polymer blends ${ }^{3,26,38-}$ ${ }^{40}$ because of the $4 \mathrm{VPh}$ unit is an efficient proton-donor species that quickly produces the hydrogen bond due to the favorable spatial disposition of the hydroxyl group in the para- position of the aromatic ring ${ }^{23}$. By molecular similitude, TDP and MDP can be considered as low molecular weight models of $\mathrm{P} 4 \mathrm{VPh}$, which have a significant trend towards hydrogen bonding formation ${ }^{20}$ ${ }^{23}$. Thus, the FTIR results confirm the behavior observed by DSC for the blends $\mathrm{C}$ and $\mathrm{D}$ as a significant intermolecular affinity between the blend components. When the macromolecular component is P2VPy (i. e., blends G and H), the shifting of the pyridine ring band in the infrared spectra is also detected as a consequence of hydrogen bond formation. However, no $\mathrm{Tg}$ variation is observed by DSC, which was attributed to a comparatively lower interaction degree due to sterical hindrance.

The compatibility between poly(vinylpyridine)s and the LMWC was also studied by thermogravimetric analysis (TGA), a complementary way of analysis. For that, the thermal decomposition profiles were obtained for both the blends (with their different compositions) and for the pure components. Figure 6 shows the decomposition profiles obtained for the blends $\mathrm{C}$ and $\mathrm{H}$ as representative examples. In general, intermediate curves in relation to the pure components are obtained. This behavior has been previously described for some polymer-polymer systems $\mathrm{s}^{41,42}$ and can be considered as additional evidence of miscibility. Moreover, the obtained decomposition profiles were used as a previous antecedent for determining the temperature intervals in which the DSC thermograms were obtained.
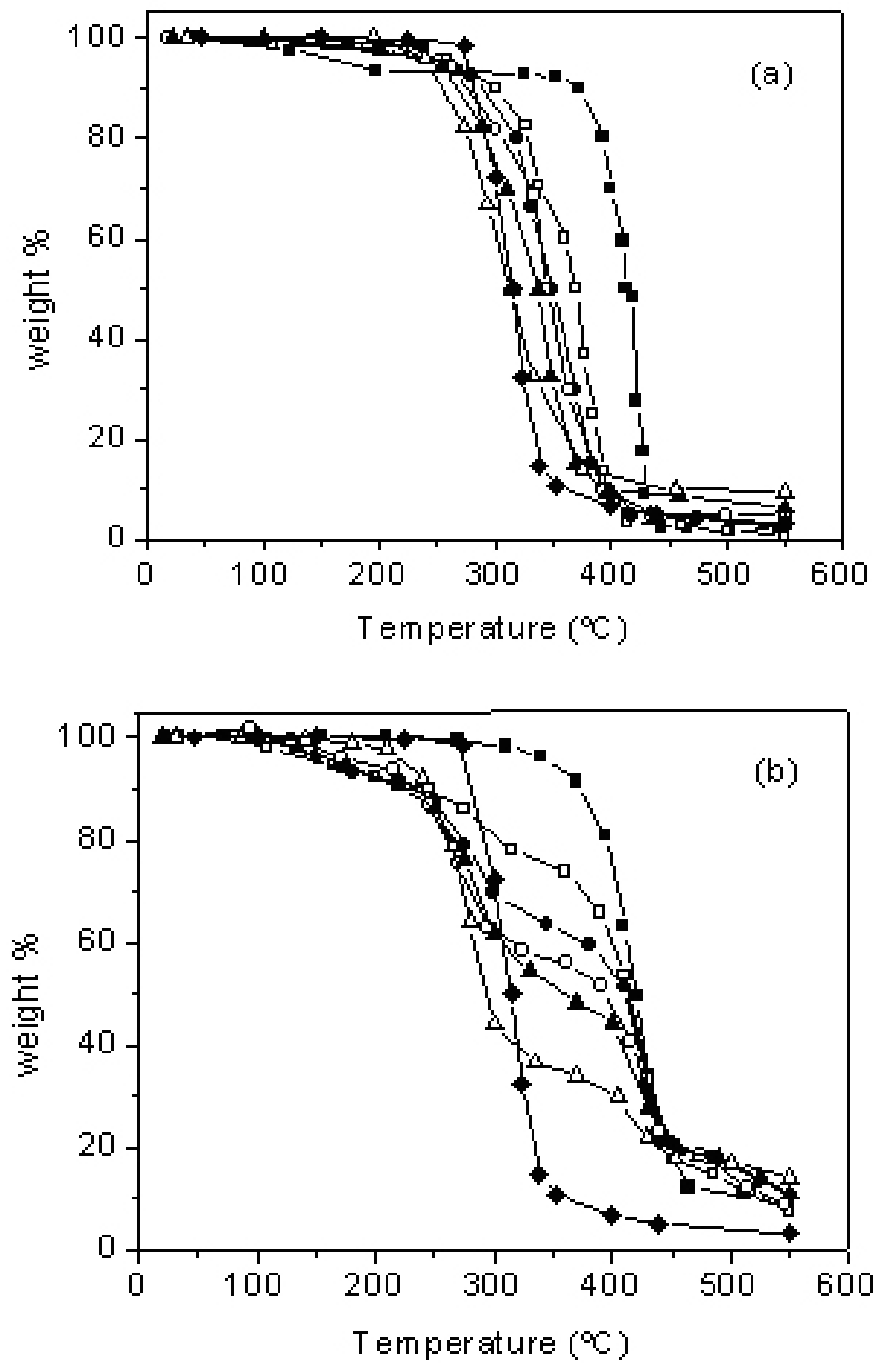

Figure 6. Thermal decomposition profiles of a) $\mathrm{C}$ and b) $\mathrm{H}$ blends.[C1,

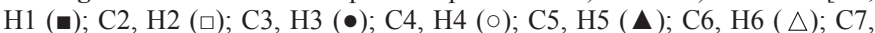
$\mathrm{H} 7(\bullet)]$

From the thermal decomposition curves of the studied systems (like those presented in Figure 6), the temperature at which the weight reduction reaches 50 $\%\left(\mathrm{~T}_{50}\right)$ was determined for the blends and the pure components. $\mathrm{T}_{50}$ represents the decomposition degree for each sample. Figure 7 presents the obtained results. $T_{50}$ decreases with the increase of TDP and MDP content. The mixture of the LMWC with P4VPy and P2VPy results in a drop in the macromolecules' thermal stability as the system becomes richer in the respective LMWC. 


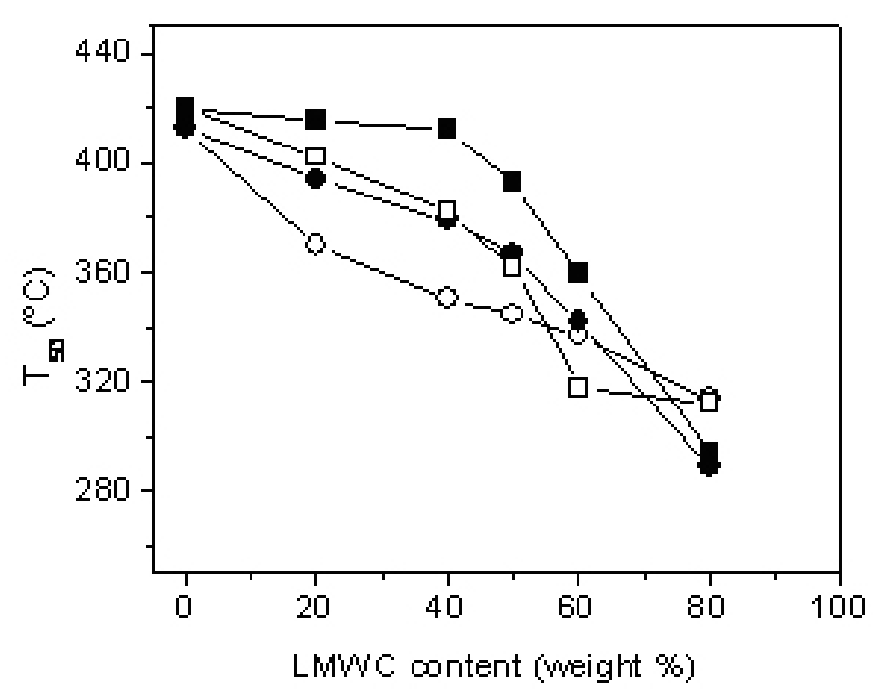

Figure 7. Variation of $\mathrm{T}_{50}$ with the composition for the studied blends. [C $(\circ), \mathrm{D}(\bullet), \mathrm{G}(\square)$ and $\mathrm{H}(\boldsymbol{\bullet})]$

Viscometry is a simple analytical technique commonly used to characterize polymeric materials. Their dissolution in a determined solvent produces significant changes in the resultant solution's viscosity. The procedure requires a total mixture at the molecular level; it is simple and independent of the blend components` morphological state. Additionally, viscosity-composition plots can also be used to detect conformational changes that can be produced as a consequence of the blending processes. Using the Solomon-Gotessman expression $^{31}$, the intrinsic viscosity $([\eta])$ was determined for the studied blends. Figure 8 displays the variation of $[\eta]$ with the composition expressed as weight $\%$ of the LMWC. When the polymer component is P4VPy, an evident diminution of the viscosity is observed as the LMWC content increases. In principle, this result is expected because when the content of LMWC increases, the content of the macromolecular component decreases. However, the variation obtained is a significant diminution, even higher than the case of blends of TDP and MDP with P(MMA-co-MA) reported by us as the first part of this work ${ }^{23}$. This behavior can be attributed to a compacting of the P4VPy chains due to the competition for the macromolecules between the LMWC molecules and the solvent molecules, as reported for other polymer-LMWC blends ${ }^{43}$. Thus, it is possible to propose the formation of a complex structure between the P4VPy and LMWC molecules, which disadvantages the polymersolvent interaction. When the polymer component is P2VPy, no significant diminution of $[\eta]$ is observed as the content of LMWC increases, reflecting the lower affinity between the components of the blends $\mathrm{G}$ and $\mathrm{H}$. This behavior is also in agreement with the DSC results.

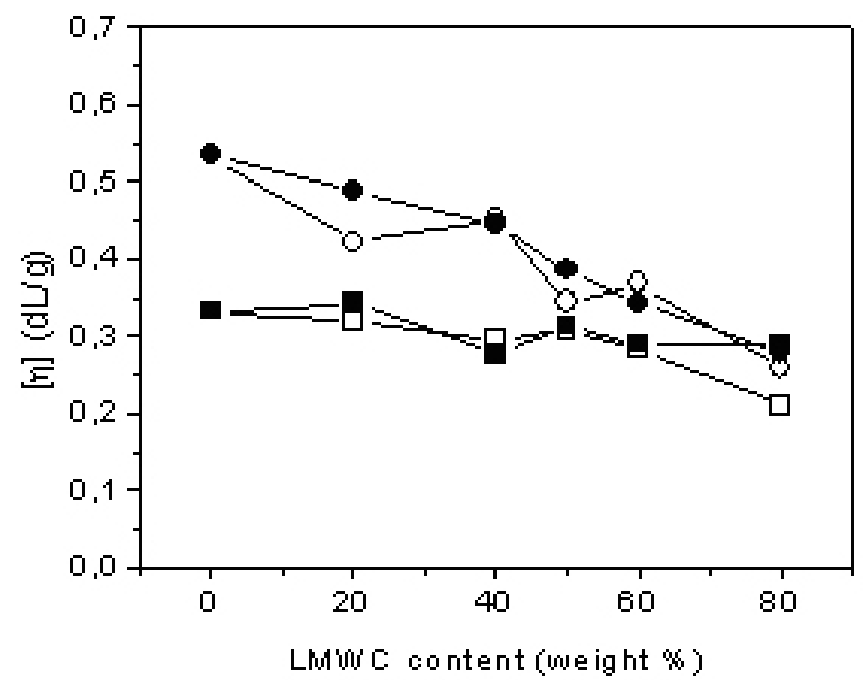

Figure 8. Variation of the intrinsic viscosity ([ๆ]) with the composition for

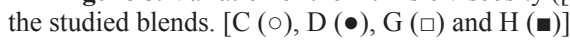

\section{CONCLUSIONS}

Miscible blends formed by functionalized vinyl polymers and low molecular weight compounds were prepared. The influence of interacting functional groups on the thermal properties of the obtained materials is revealed.

A plasticizing effect of TDP and MDP on P4VPy is observed, i. e., a decrease of the glass transition temperature values as the content of LMWC increases. This effect is not detected when TDP and MDP are blended with P2VPy, which was attributed to a comparatively lower interaction level.

The melting temperature and fusion molar heat of the LMWC decrease with the polymer component content. The crystallinity and the molecular order of TDP and MDP diminish as the blend is richer in P4VPy and P2VPy.

Thermal stability of the studied poly(vinylpyridine)s is affected by the addition of TDP and MDP. In all the cases, $\mathrm{T}_{50}$ decreases with the increase of the LMWC content.

Significant shifts of infrared absorption bands are observed. The signal corresponding to the deformation vibration of the pyridinic ring of P4VPy and P2VPy is moved toward higher wave number values. This behavior is indicative of the formation of hydrogen bonding between the blend components as main way of intermolecular interaction.

\section{ACKNOWLEDGEMENTS}

We express our thanks to Dirección de Investigación Universidad de Concepción, Grant 203.024.026-1.0 for financial support.

\section{REFERENCES}

1. J. Lee, P. Painter, M. Coleman, Macromolecules 21, 954, (1988).

2. M. Rocha, Revista de Plásticos Modernos 440, 149, (1993).

3. M. Xiang, M. Jiang, Y. Zhang, C. Wu, L. Feng, Macromolecules 30, 2313, (1997).

4. L. Parada, L. Cesteros, E. Meaurio, I. Katime, Polymer 39, 1019, (1998).

5. C. De Kesel, C. Lefèbre, J. Nagy, C. David, Polymer 40, 1969, (1999).

6. H. Jeong. M. Rooney, D. David, W. Mac Knight, F. Karasz, T. Kajiyama, Polymer 41, 6003, (2000).

7. (a) S. Wei Kuo, C. Lung Lin, F. Chih Chang, Polymer 43, 3943, (2002). (b) N. Haddadine-rahmoun, F. Amrani, V. Arrighi, J. M. G. Cowie, Eur. Polym. J. 44, 821, (2008).

8. (a) A. Bhutto, D. Vesely, B. Gabrys, Polymer 44, 6627, (2003). (b) L. Cui, J. T. Yeh, K. Wang, Q. Fu, J. Polym. Sci. Polym. Phys. 46, 1360, (2008).

9. (a) J. Z. Yi, S. H. Goh, Polymer 46, 9170, (2005). (b) K. Suknuntha, V. Tantishaiyakul, V. Vao-Soongnern, Y. Espidel, T. Cosgrove, J. Polym. Sci. Polym. Phys. 46, 1258, (2008).

10. C. F. Huang, S. W. Kuo, F. J. Lin, C. F. Wang, C. J. Hung, F. C. Chang, Polymer 47, 7060, (2006).

11. E. Kiran, K. Liu, K. Ramsdell, Polymer 49, 1853, (2008).

12. C. Tibirna, P. N. Diouf, Polymer 49, 241, (2008).

13. I. Krupa, G. Miková, A. S. Luyt, Eur. Polym. J. 43, 4695, (2007).

14. Y. He, N. Asakawa, Y. Inoue, J. Polym. Sci. Polym. Phys. 38, 1848, (2000).

15. R. Kirk, D. Othmer, "Encyclopedia of Chemical Technology”, John Wiley \& Sons, $4^{\text {th }}$ Ed., vol. 3, 435, 1991.

16. R. Kirk, D. Othmer, "Encyclopedia of Chemical Technology", John Wiley \& Sons, $4^{\text {th }}$ Ed., vol. $2,18,1991$.

17. T. Watanabe, Y, He, N. Asakawa, N. Yoshie, Y. Inoue, Polym. Int. 50, $463,(2001)$

18. K. M. Shin, T. Dong, Y. He, Y. Inoue, J. Polym. Sci. Polym. Phys. 43, 1433, (2005).

19. G. L. Yuan, N. Kuramoto, Polymer 44, 5501, (2003).

20. J. Li, Y. He, Y. Inoue, J. Polym. Sci. Polym. Phys. 39, 2108, (2001).

21. Y. He, N. Asakawa. Y. Inoue, Macromol. Chem. Phys. 202, 1035, (2001).

22. Y. He, N. Asakawa, Y. Inoue, J. Polym. Sci. Polym. Phys. 38, 1848, (2000).

23. N. Gatica, N. Alvarado, D. Sepúlveda, J. Chil. Chem. Soc. 51, 945, (2006).

24. L. Cesteros, E. Meaurio, I. Katime, Macromolecules 26, 2323, (1993).

25. J. Moore, S. Kaur, Macromolecules 31, 328, (1998).

26. J. Wang, M. K. Cheung, Y. Mi, Polymer 42, 3087, (2001).

27. J. Yi, S. Goh, Polymer 42, 9313, (2001). 
28. M. Maldonado-Santoyo, L. Cesteros, I. Katime, S. M. Nuño-DonLucas, Polymer 45, 5591, (2004).

29. S. Liu, C. M. Chan, L. T. Weng, M. Jiang, J. Polym. Sci. Polym. Phys. 43, 1924, (2005).

30. B. Liu, W. Zhang, S. Zheng, Q. Guo, J. Polym. Sci. Polym. Phys. 44, 1618, (2006).

31. O. Solomon, B. Gotessman, Makromol. Chem. 104, 177, (1967).

32. A. Kumar, R. Gupta, Fundamentals of Polymer Engineering, Marcel Dekker, 2nd Ed., 449, 2003.

33. A. Sanchís, M. G. Prolongo, C. Salom, R. M. Masegosa, J. Polym. Sci. Polym. Phys. 36, 95, (1998).

34. (a) Y. K. Han, E. M. Pearce, T. K. Kwei, Macromolecules 33, 1321 , (2000). (b) D. Ratna, T. Abraham, J. Karger-Kocsis, Macromol. Chem. Phys. 209, 723, (2008).
35. (a) H. Lü, S. Zheng, B. Zhang, X. Tang, Macromol. Chem. Phys. 205, 834, (2004). (b) T. Ohno, Y. Nishio, Macromol. Chem. Phys. 208, 622, (2007).

36. (a) J. Shen, S. Zheng, J. Polym. Sci. Polym. Phys. 44, 942, (2006). (b) Y. Ghebremeskel, R. A. Weiss, J. Polym. Sci. Polym. Phys. 46, 1602, (2008).

37. L. Cesteros, Revista Iberoamericana de Polimeros 5, 111, (2004).

38. Y. Liu, S. H. Goh, S. Y. Lee, Macromolecules 32, 1967, (1999).

39. E. M. Woo, C. P. Chiang, Polymer 45, 8415, (2004).

40. L. T. Ting, E. M. Woo, J. Polym. Sci. Polym. Phys. 44, 1339, (2006).

41. D. Racic', N. Gatica, L. Gargallo, Polimery 46, 823, (2001).

42. E. Meaurio, J. Velada, L. Cesteros, I. Katime, Macromolecules 29, 4598, (1996).

43. L. Gargallo, N. Gatica, D. Radic', Int. J. Polym. Mater. 27, 107, (1994). 